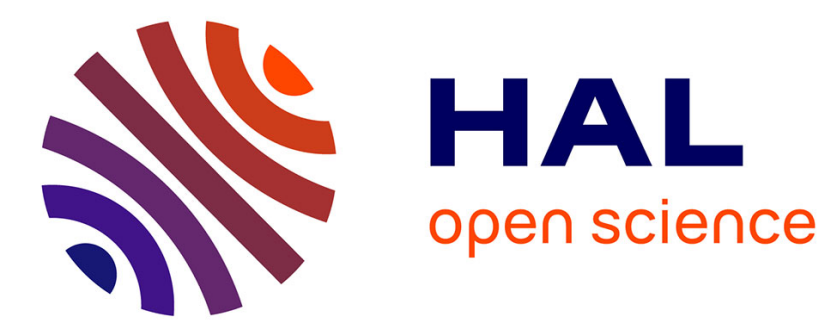

\title{
PLM in Engineering Education: A Pilot Study for Insights on Actual and Future Trends
}

Joel Sauza Bedolla, Gianluca D’antonio, Frédéric Segonds, Paolo Chiabert

\section{To cite this version:}

Joel Sauza Bedolla, Gianluca D'antonio, Frédéric Segonds, Paolo Chiabert. PLM in Engineering Education: A Pilot Study for Insights on Actual and Future Trends. 14th IFIP International Conference on Product Lifecycle Management (PLM), Jul 2017, Seville, Spain. pp.277-284, 10.1007/978-3-31972905-3_25. hal-01764219

\section{HAL Id: hal-01764219 \\ https://inria.hal.science/hal-01764219}

Submitted on 11 Apr 2018

HAL is a multi-disciplinary open access archive for the deposit and dissemination of scientific research documents, whether they are published or not. The documents may come from teaching and research institutions in France or abroad, or from public or private research centers.
L'archive ouverte pluridisciplinaire HAL, est destinée au dépôt et à la diffusion de documents scientifiques de niveau recherche, publiés ou non, émanant des établissements d'enseignement et de recherche français ou étrangers, des laboratoires publics ou privés. 


\title{
PLM in Engineering Education: a pilot study for insights on actual and future trends
}

\author{
Joel Sauza Bedolla ${ }^{1}$, Gianluca D’Antonio ${ }^{1}$, Frédéric Segonds ${ }^{2}$, Paolo Chiabert ${ }^{1}$ \\ ${ }^{1}$ Politecnico di Torino, corso Duca degli Abruzzi 24, 10129, Torino, Italy \\ \{joel.sauza, gianluca.dantonio, paolo.chiabert\}@polito.it \\ ${ }^{2}$ Ecole Nationale Supérieure d'Arts et Métiers, 151 bd. de l'Hôpital, 75013, Paris, France \\ frederic.segonds@ensam.eu
}

\begin{abstract}
Universities around the world are teaching PLM following different strategies, at different degree levels and presenting this approach from different perspectives. This paper aims to provide preliminary results for a comprehensive review concerning the state of the art in PLM education. This contribution presents the design and analysis of a questionnaire that has been submitted to academics in Italy and France, and companies involved in a specific Master program on PLM. The main goal of the survey is to collect objective and quantitative data, as well as opinions and ideas gained from education expertise. The collected results enable to depict the state of the art of PLM education in Italian universities and to gain some insights concerning the French approach; the structure of the survey is validated for further worldwide submission.
\end{abstract}

Keywords: Product Lifecycle Management; Education; Survey.

\section{Introduction}

Product Lifecycle Management (PLM) is a key factor for innovation. The PLM approach to support complex goods manufacturing is now considered as one of the major technological and organizational challenges of this decade to cope with the shortening of product lifecycles [1]. Further, in a globalized world, products are often designed and manufactured in several locations worldwide, in "extreme" collaborative environments.

To deal with these challenges and maintain their competitiveness, companies and professional organizations need employees to own a basic understanding of engineering practices, and to be able to perform effectively, autonomously, in a team environment [2]. Traditional methodologies for design projects (i.e. with collocated teams and synchronous work) could be effective until a few decades ago, but they are insufficient nowadays. 
Thus, engineering education has changed in order to provide students with some experience in collaborative product development during their studies. It is essential to train students to Computer Supported Collaborative Work (CSCW) [3], and PLM is a means for students to structure their design methodology. Indeed, before starting an efficient professional collaboration, future engineers must be mindful of how this approach works, and how tasks can be split between stakeholders. Thus, from an educational point of view, the PLM approach can be considered as a sophisticated analysis and visualization tool that enables students to improve their problem solving and design skills, as well as their understanding of engineering systems behaviour [2]. Moreover, PLM can also be a solution to face one of the main problems in our educational system: the fragmentation of the knowledge and its lack of depth [3].

The main research question from here is: "How can we, as engineering educators, respond to global demands to make our students more productive, effective learners? And how can PLM help us to achieve this goal?". At the state of the art, the information about PLM education is fragmented. Hence, the aim of this paper is to propose a survey structure to collect quantitative data about the existing university courses in PLM, identify the most common practices and possible improvements to closer adhere to the needs of manufacturers.

The remainder of the paper is organized as follows: in section 2, an analysis of literature concerning recent changes in educational practices in engineering education is presented and the state of the art of PLM education is settled. Then, the survey structure is presented in section 3 . The results are presented in section 4: data collected from Italian universities are presented, as well as the results of the test performed in France to validate the survey structure. Finally, in section 5, some conclusive remarks and hints for future work are provided.

\section{State of the art}

In literature, there is no evidence of a complete and full review of how PLM is taught in higher institutions around the world. Still, partial works can be found. Gandhi [4] presents the educational strategy employed by three US universities. Fielding et al. [5] show examples of PLM and collaborative practices implemented in higher education institutions from the United States and France. Sauza et al. [6] performed a two-step research. The first attempt consisted in a systematic research of keywords (i.e. PLM education, PLM certification, PLM course, PLM training) in the principal citation databases. Nevertheless, the analysis of scientific literature was limited to some specific programs of a limited quantity of countries. For this reason, the research was extended to direct research on universities' websites. The inclusion criteria for institutions was the attendance to one of the two main events in scientific and industrial use of PLM: (i) the IFIP working group 5.1 PLM Inter- 
national Conference, and (ii) Partners for the Advancement of Collaborative Engineering Education. The review process covered 191 universities from Europe, Asia, America and Oceania. It was found that there is a high variety in the topics that are presented to students, departments involved in the course management, the education strategy and the number of hours related to PLM.

The analysis presents useful insights. However, the research methodology based on website analysis was not sufficient and may present some lacks. In some cases, websites did not present a "search" option and this limited the accessibility to information. Moreover, during the research, some issues with languages were experienced: not all of the universities offered information in English, and for this reason, the universities were not considered. In some other cases, information was presented in the curricula that can be accessed only to institution members. The specific didactics nature of this study is precisely in that it brings researchers and professors from engineering education to work explain their vision of how PLM is taught. The objective is to get real participatory innovation based on integration of the PLM within a proven training curriculum in engineering education. One step further, we prone that by stimulating the desire to appropriate knowledge, innovative courses are also likely to convince a broad swath of students averse to traditional teaching methods and much more in phase with their definition as "digital natives" [7]

This paper is intended to be the first step of a broader effort to map the actual situation of PLM education around the world. This contribution presents the methodology employed to scientifically collect information from universities. Before going global, a first test has been made to evaluate the robustness of the tool in the authors' countries of origin, where the knowledge of the university system structure was clear.

\section{Methodology}

In order to get insights on the state of the art in PLM education, a survey structured in three parts has been prepared.

The first part is named "Presentation": the recipient is asked to state the name of his institution and to provide an email address for possible future feedbacks. Further, he is asked to state whether he is aware about the existence of courses in PLM in his institution or not, and if he is in charge of such courses. In case of positive reply, the recipient is invited to fill the subsequent part of the survey.

The second part of the survey aims to collect objective information to describe the PLM course. In particular, the following data are required:

- The level at which the course is taught (among B.Sc, M.Sc, Ph.D, Master);

- The curriculum in which the course is taught (free reply);

- At which year the course is taught, and the overall duration of the curriculum (values constrained between 1 and 5); 
- The department in charge of the course (free reply);

- If PLM is taught in a devoted course (Yes/No) or as a topic in a broader course (Yes/No);

- The name of the course (free reply) and its duration;

- If software training is included (Yes/No) and which software is used.

Finally, in the third part of the survey, subjective data are collected to measure the interest of the recipient in teaching the PLM approach and the interest of the students in this topic (both in a likert 1-5 scale). Further, an opinion about the duration of the course is required (not enough/proper/excessive) and whether the presentation of applied case studies or the contribution of industrial experts are included in the course. A space for further free comments is also available.

The invitations to fill the survey have been organized in two steps. First, a full experiment has been made in Italy. The official database owned by the Italian Ministry of Education and University has been accessed to identify the academics to be involved. In Italy, academics are grouped according to the main topic of their research. Therefore, the contacts of all the professors and researchers working in the closest topics to PLM have been downloaded, namely: (i) Design and methods of industrial engineering; (ii) Technologies and production systems; (iii) Industrial plants; (iv) Economics and management Engineering; (v) Information elaboration systems; (vi) Computer science. This research led to a database consisting of 2208 people from 64 public universities. A first invitation and a single reminder have been sent; the survey, realized through a Google Form, has been made accessible online for 2 weeks in January 2017.

The second step consisted in inviting a small set of academics from French universities through focused e-mails: 11 replies have been collected. 11 replies have been collected. Further, a similar survey has been submitted to French companies employing people that has been attending a Master in PLM in the years 2015 and 2016.

\section{Survey data analysis}

\subsection{Results from the Italian sample}

The overall number of replies from Italian academics is equal to 213 , from 49 different institutions. Among this sample, 124 people do not have information about PLM courses in their universities; therefore, they were not asked further questions. The 89 respondents aware about a PLM course belong to 36 universities; among them, 40 professors are directly involved in teaching PLM. A synthetic overview of the results is provided in Fig. 1; the map of the Italian universities in which PLM is taught is shown in Fig. 2. 


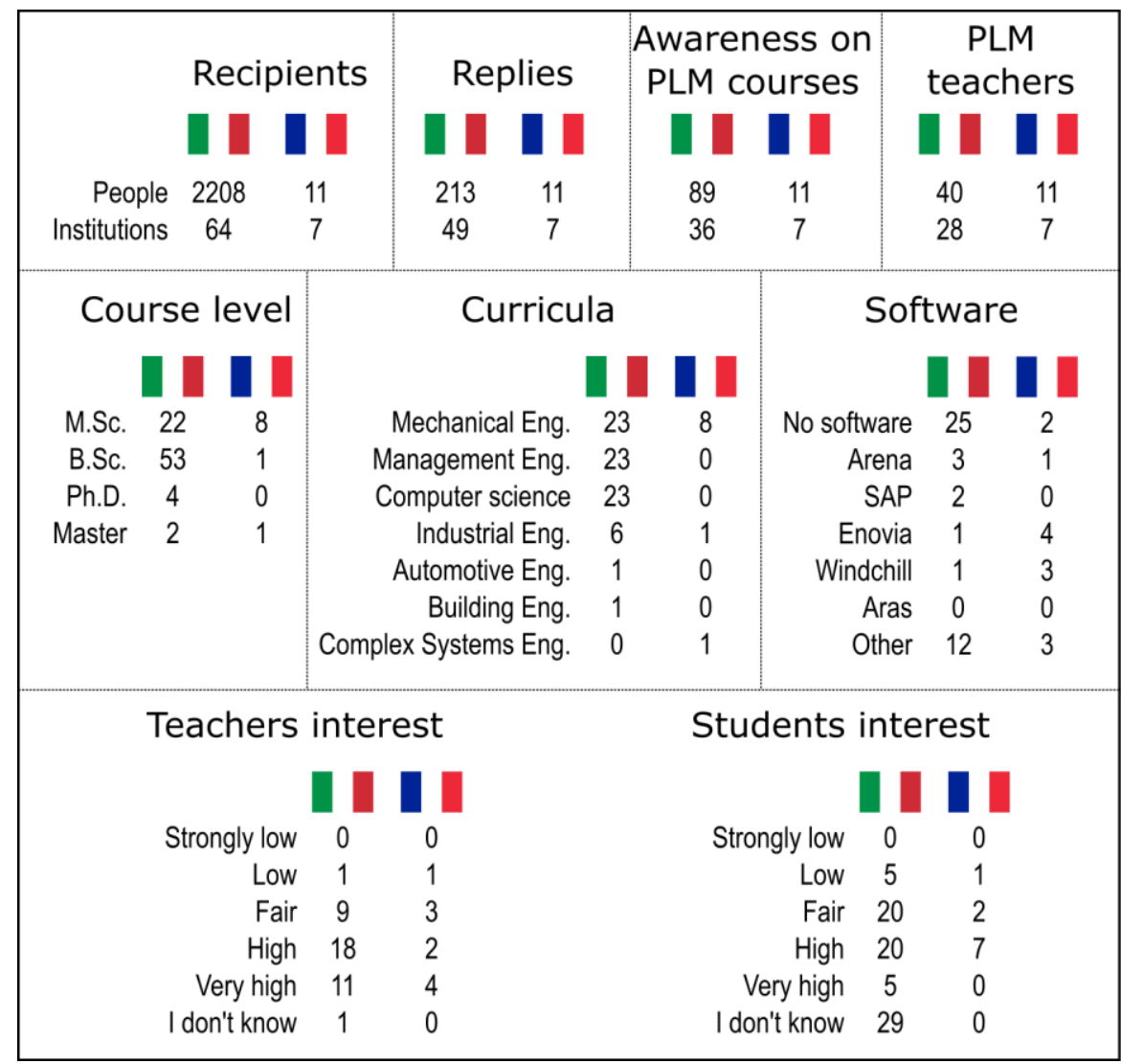

Fig. 1. Synthesis of the results obtained through both the Italian and the French PLM teachers.

Degree level. In the sample of 36 universities, PLM is taught at different levels. The Master of Science is the most common: 53 courses have been identified. In 22 cases, PLM is also taught at the Bachelor level. Furthermore, there are 4 courses devoted to Ph.D. candidates and 2 Masters are organized. The latter two Master courses are organized in the Polytechnic universities of Torino and Milano; however, the first one has recently moved to University of Torino.

Curricula. There is a variety of curricula involved in teaching PLM. Course for Management Engineering and Mechanical Engineering are organized (23 occurrences each). The area of Computer Science is also involved (23 occurrences): topics concerning the architecture of PLM systems, or the so-called Software Lifecycle Management are taught. Moreover, PLM courses are also provided in Industrial Engineering (6 occurrences), Automotive Engineering (B.Sc. at Polytechnic University di Torino) and Building Engineering (Ph.D. course at Politecnico di Bari).

Type of course. The teachers involved in teaching PLM state that this topic is mostly dealt in broader courses, such as Drawing, Industrial Plants, Management. 


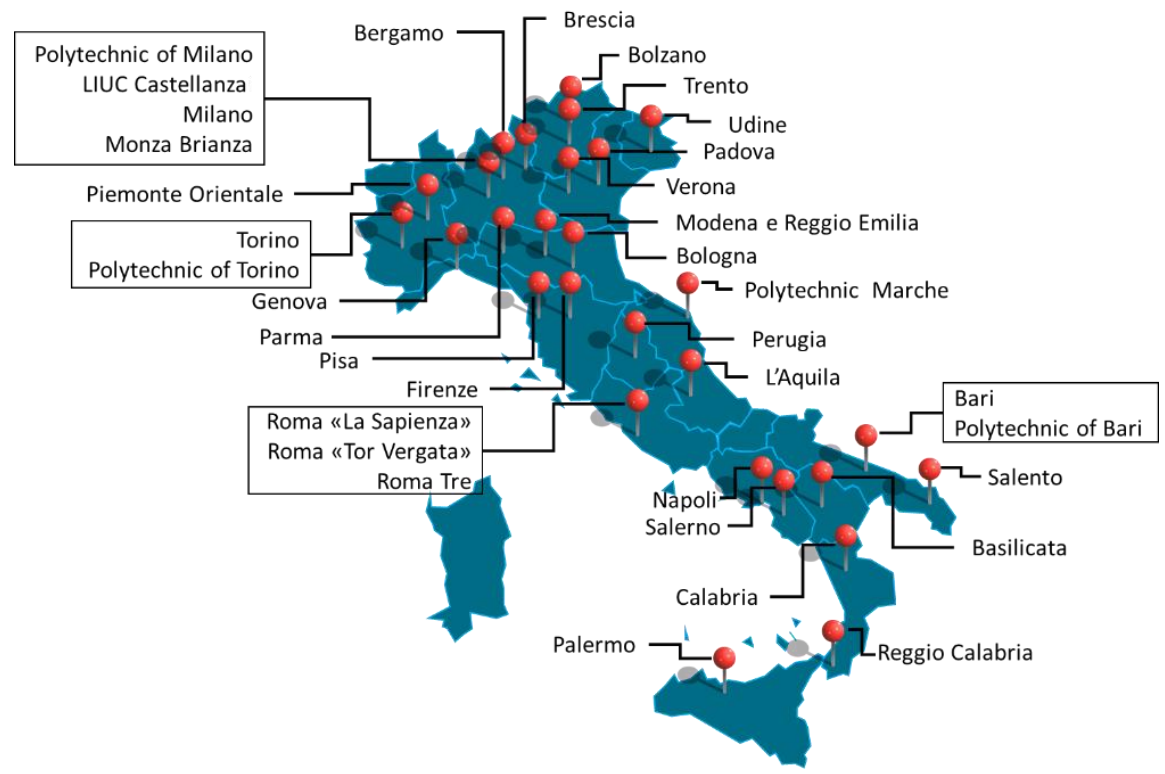

Fig. 2. Map of the Italian universities in which PLM is taught.

A devoted course is organized only in three cases: (i) "Product Lifecycle Management" at Polytechnic University of Milano (M.Sc. course for Management Engineers, 50 hours); (ii) "Methods and tools for product lifecycle management" at University of Bergamo (M.Sc. course for Management Engineering, 48 hours); (iii) the aforementioned Master course held in Torino.

Practical activities. Among the 40 PLM teachers, 25 of them do not use software to support their educational activity. Some courses deploy Arena, Enovia, the PLM module embedded in SAP, Windchill. Other solutions, developed by smaller software houses are also used. Among the respondents, no one uses Aras Innovator, a PLM solution that has a license model inspired by open source products. However, in the majority of the teachers (27), industrial case studies are presented to show the role of PLM in managing product information and to provide students with a practical demonstration of the possible benefits coming from its implementation. Furthermore, interventions from industrial experts, aiming to show the practical implications of the theoretical notions taught in frontal lectures, are planned by 21 teachers.

Interest in PLM. The interest of students in PLM is variable: the replies are equally distributed among "Low" or "Fair" (25 occurrences) and "High" or "Very high" (25 occurrences). The interest of replicants in PLM is variable too: 34 people replied "Strongly low", "Low" or "Fair"; 34 people replied "High" or "Very high"; the remainder sample states "I don't know". As expected, the interest in PLM of people teaching this topic is high: 29 people replied "High" or "Very high" (out of a sample of 40 teachers). 


\subsection{Results from the French sample}

On the French side, 11 replies were collected from 7 different Universities and School of Engineering. All the respondents teach PLM courses in their Universities. Similarly to the Italian sample, PLM is mostly taught in the M.Sc. level: beside a Master course, one B.Sc. and 8 M.Sc. courses were mapped. Most of the courses (8) are devoted to Mechanical Engineers. In 6 cases, a specific course is designed for PLM; further, in the Ecole supérieure d'électricité settled in Châtenay-Malabry the so-called 'PLM week' is organized. The duration of the PLM courses mainly ranges between 32 and 64 hours, which is an appropriate duration, according to the teachers; conversely, in the broader courses, the time spent in teaching PLM is lower than 6 hours. The only Master mapped through the survey is held in Ecole Nationale Supérieure d'Arts et Métiers (Paris): the duration is equal to 350 hours, with high interest of the participants.

A reduced version of the survey was also sent to a small set of French companies to map internal courses in PLM.7 replies have been obtained.: 3 were from large companies in the field of aeronautics, textile and consulting, and 4 were small-medium companies from the PLM and BIM sector. 57\% of these companies declare they have courses dedicated to PLM. The name of the courses are various. In particular, a textile enterprise has course structured in 11 modules as business process:

1. Line plan Management

2. Color Management

3. Material Management

4. Product/ Colorway Merchandising Management,

5. Material. Color Development and Approval management

6. Product Specification management,

7. Market and Distribution Selection

8. Product Sample/ Approval management,

9. Supplier Management and Vendor Collaboration

10. Reports and Dashboards

11. Quality Management

Another company has a specific training course on PLCS Training Over-view and PLCS Training Technical Walkthrough; focused on data management using standards. Time for these courses ranges from 2 to 40 hours, depending on the complexity of the concept developed.

\section{Conclusions}

The present paper presented a methodology for a systematic overview about university education in PLM. A survey has been submitted to all the Italian academics performing research and teaching activities in fields related with PLM. The percentage of respondents in the Italian experiment was approximately $10 \%$, which is in line with the expectations of the authors: these replies enabled to identify PLM 
courses in 36 different universities, mainly located in the north-central part of the country, which is characterized by a higher density of industries. However, to have a successful realization of the survey a complete database of university teachers is mandatory.

The proof-of-concept realized on the French sample led to good results: no criticalities have been found in the survey. Hence, the next steps of the work are the creation of the recipients database and the full-scale experiment. Then, the experiment can be replicated in other countries, to have a more exhaustive picture about PLM education. We plan to rely on Bloom taxonomy of educational objectives to sharpen the skills taught in PLM courses [8].

Our research question was: "How can we, as engineering educators, respond to global demands to make our students more productive, effective learners? And how can PLM help us to achieve this goal?". A first insight given to this research question is the proposal, as an ultimate goal, of the creation of a network made of PLM teachers, that will enable mutual exchange of expertise, teaching material, exercises and practices. To reach this goal and to wider our approach to IFIP WG $5.1 \mathrm{com}-$ munity, a first step could be the creation of shared storage space for documents that allow any user to teach PLM at any level.

\section{Acknowledgments}

The authors are grateful to the colleagues and industrials that replied to the survey.

\section{References}

[1] M. Garetti, S. Terzi, N. Bertacci and M. Brianza, "Organisational change and knowledge management in PLM implementation," International Journal of Product Lifecycle Management, vol. 1, no. 1, pp. 43-51, 2005.

[2] Z. Chen and Z. Siddique, "Web-based mechanical engineering design education environment simulating design firms," in Innovations in Engineering Education 2004: Mechanical Engineering Education, Mechanical Engineering Technology Department Heads, Anaheim, USA, 2004.

[3] C. Pezeshki, R. Frame and B. Humann, "Preparing undergraduate mechanical engineering students for the global marketplace - New demands and requirements," in ASEE Annual Conference Proceedings, Salt Lake City, USA, 2004.

[4] P. Gandhi, "Product Lifecycle Management in Education: Key to Innovation in Engineering and Technology," in 11th IFIP WG 5.1 International Conference, PLM 2014, Yokohama, 2014. 
[5] E. A. Fielding, J. R. McCardle, B. Eynard, N. Hartman and A. Fraser, "Product lifecycle management in design and engineering education: International perspectives," Concurrent Engineering: Research and Applications, vol. 22, no. 2, pp. 123-134, 2014.

[6] J. Sauza-Bedolla, J. Mora-Orozco, A. Guarin-Grisales, G. D'Antonio and P. Chiabert, "PLM in a didactic environment: the path to smart factory," Int. J. Product Lifecycle Management, vol. 9, no. 4, pp. 333-352, 2016.

[7] M. Prensky, "Digital natives, digital immigrants. Part 1," On the Horizon, vol. 9, no. 5, pp. 1-6, 2001.

[8] B. S. Bloom, D. R. Krathwohl and B. B. Masia, Bloom taxonomy of educattional objectives, Boston: Allyn and Bacon, 1984. 